\title{
A one year survey of motor vehicle accidents in Rafsanjan, Iran, in 2014
}

\author{
Esmaeili $\mathrm{A}, \mathrm{PhD}^{1}$, Rezaeian $\mathrm{M}, \mathrm{PhD}^{2}$, Sanji $\mathrm{M}, \mathrm{MD}^{3}$, Sheikh Fathollahi M, $\mathrm{PhD}^{4}$, Mortavazi $\mathrm{SM}$, \\ $\mathrm{MD}^{-\mathrm{MPH}^{5}}$, Ghasemi HR, MD-GP ${ }^{6}$, Vazirinejad R, $\mathrm{PhD}^{*^{7}}$ \\ 1-Associated Prof., Dept. of Social Medicine, Occupational Environmental Research Center, Medical School, Rafsanjan \\ University of Medical Sciences, Rafsanjan, Iran. 2. Professor, PhD of Epidemiology, Dept. of Epidemiology and Biostatistic, \\ Occupational Environmental Research Center, Medical School, Rafsanjan University of Medical Sciences, Rafsanjan, Iran. \\ 3- Assistant Prof., Dept. of Emergency, Rafsanjan University of Medical Sciences, Rafsanjan, Iran. 4- Assistant Prof., Dept. \\ of Social Medicine and Occupational Environment Research Center, Medical School, Rafsanjan University of Medical \\ Sciences, Rafsanjan, Iran.5- Master of Public Health, Disaster \& Emergency Management Center, Rafsanjan University of \\ Medical Sciences, Rafsanjan, Iran. 6-General Practitioner, Medical School, Rafsanjan University of Medical Sciences, \\ Rafsanjan, Iran. 7- Professor, PhD of Epidemiology, Social Determinants of Health Research Centre, Medical School, \\ Rafsanjan University of Medical Science, Rafsanjan, Iran.
}

Background: Injuries and accidents are one of the main problems in the present century. The purpose of this study was the identification and analysis of the characteristics of pre-hospital emergency motor vehicle accidents (MVA) in Rafsanjan, Iran, in 2014.

Materials and Methods: This cross-sectional descriptive study was performed on all patients recorded by pre-hospital emergency during a period of one year (from 21 March 2013 to 20 March 2014). Our data were obtained from a crash record book kept at pre-hospital emergency dispatch. The crash database variables include age and gender of victims, vehicle type, type of collision, response time, location, and crash hotspots, and severity of injury. Accident data have been analyzed in SPSS software.

Results: In 2014, 1878 injured patients were transported to the general hospital by pre-hospital emergency dispatch. The mean age of victims was $29.10 \pm 15.65$ years, with the age range of 1-95 years. Among these cases, $85.8 \%$ were men and $14.2 \%$ were women. The majority of the patients (56.7\%) were in the age range of 15-29 years, 30-44 years $(20.6 \%)$, and $46-65$ years $(10.8 \%)$, respectively. Motorcycle accidents were the major cause of injuries $(48.6 \%)$, and 4 patients $(0.2 \%$ of all cases) died on the accident scene.

Conclusions: In the present study, motorcycle accidents constitute the majority of cases of MVAs. Therefore, safety training targeted at motorcyclists would be one of the best interventions for the prevention and controlling of trauma due to MVAs. This intervention could be the most efficient among younger drivers.

Keywords: Injuries, Accidents, Motor Vehicle, Emergency.

\section{Introduction}

Injuries are amongst issues of grave concern within societies. They result in the deaths of countless individuals and disabilities in thousands of others. Many significant psychological disorders in families and economical burden on countries and communities are also associated with accidents and their resulting injuries (1-5). It was estimated that approximately $10 \%$ of all of injuries lead to death. It is also estimated that
16000 deaths daily worldwide are related to injuries. This figure is equivalent to 5.8 million deaths due toaccidents each year, which is more than the total number of deaths due to HIV, tuberculosis, and malaria (3.8 million) $(5,6)$. In many countries, injuries have been reported as the $3^{\text {rd }}$ health problem after

\footnotetext{
Corresponding author: Reza Vazirinejad, Social Determinants of Health Research Centre, Medical School, Rafsanjan University of Medical Science, Rafsanjan, Iran.

Email: rvazirinejad@yahoo.co.uk
} 
cardiovascular diseases and cancer; furthermore, $90 \%$ of deaths from injuries occur in low and middle income countries (5, 6).

Motor vehicle accidents (MVAs) are the most common source of injury and death around the globe. In 2002, more than 1.18 million people died in MVAs, and approximately 15 million are injured every year in MVAs worldwide. About $70 \%$ of fatalities occur among young adults aged 15-44 years, and in many countries, MVAs have become the main cause of death among men in this age group. MVAs have become a major health burden in all societies in the $21^{\text {st }}$ century (7-10).

In Iran, a large number of injuries and deaths due to MVAs have been reported in the last few years. Due to the high social and economic cost of road accidents and their physical and psychological effects on individuals and communities, today, traffic accidents is one of the most important topics of scientific research. Similarly, in Rafafsanjan MVAs (as the developing countries) are also social-economically very important $(11,12)$.

The purpose of this study was the identification and analysis of the characteristics of pre-hospital emergency MVA in Rafsanjan, Iran, during a period of one year (from 21 Mar 2013 to 20 Mar 2014).

\section{Materials and Methods}

The present study took place in Rafsanjan District, Kerman Province, $850 \mathrm{~km}$ South of Tehran, in the Southeast of Iran. This was a cross-sectional descriptive study. The study sample consisted of all patients referred to emergency wards during this time period. A checklist was designed based on the aim and objective of the study for the purpose of data collection. The checklist is comprised of two sections. The first section contains demographic information (e.g., age and gender). The second section of the checklist contains information about the vehicle type, type of collision, severity of injuries, response time, location and crash hotspots.
Injuries were classified into 3 groups in terms of severity (dead, major injury, and minor injury). Evaluation according to crash severity was performed by pre-hospital emergency technicians. For this reason, all technicians were trained before data collection on the evaluation of the victim's physical condition in terms of anatomic damage.

Data were analyzed using SPSS software (version 18, SPSS Inc., Chicago, IL, USA), and parametric (t-test, correlation test) and non-parametric analysis (chi-square, Fisher's exact test) tests were used where appropriate.

\section{Results}

During the year 2014, 1878 injured patients were transferred to general hospitals by prehospital emergency dispatch. In other words, 5.14 victims of city street accidents referred to the emergency department of hospitals every day. Of those, $85.8 \%$ were men and $14.2 \%$ were women (men to women ratio was 6.04:1). The mean age of victims was $29.10 \pm$ 15.65 years, with age range of $1-95$ years ( $\mathrm{min}$ $=19, \max =95$ years $)$. The majority of the patients $(56.7 \%)$ were in the age range of 15 29 years, 30-45 years (20.6\%), and 46-65 years $(10.8 \%)$, respectively. As the results show, the rate of injuries in men was more than six fold higher than that in women, and the majority of injured patients $(85.3 \%)$ were below the age of 45 years. Data on the victims and their accidents is presented in table 1.

The percentages of victims based on the type of vehicles and their age is presented in table 2. As shown in table 2, the most frequent vehicle accidents were motorcycle accidents (n $=913,48.6 \%)$ and rollovers $(\mathrm{n}=396,21.1 \%)$, respectively. Statistical analysis showed that there was a significant association between the age of victims and the vehicle they had been driving $\left(x^{2}=287.38, \mathrm{df}=16, \mathrm{P}<0.001\right)$.

More than $50 \%$ of victims were in the age range of 15-29 $(\mathrm{n}=1065)$, among which a considerable majority was injured in motorcycle accidents (57.9\%, $\mathrm{n}=617)$. Among victims in the age range of older than 
65 years of age, the highest rate of accidents

had taken place for pedestrians $(47.3 \%)$.

Table 1: Demographic characteristics of motor vehicle accident victims and data on their accidents

\begin{tabular}{|c|c|c|c|}
\hline \multicolumn{2}{|c|}{ Variables } & \multicolumn{2}{|c|}{$\begin{array}{c}\text { All motor vehicle } \\
\text { accidents }\end{array}$} \\
\hline & & $\mathbf{N}$ & $\%$ \\
\hline \multicolumn{4}{|l|}{ Gender } \\
\hline & Male & 1612 & 85.8 \\
\hline & Female & 266 & 14.2 \\
\hline \multicolumn{4}{|l|}{ Age at census } \\
\hline & $0-14$ & 151 & 8.0 \\
\hline & $15-29$ & 1065 & 56.7 \\
\hline & $30-45$ & 386 & 20.6 \\
\hline & $46-65$ & 202 & 10.8 \\
\hline & $>65$ & 74 & 3.9 \\
\hline \multicolumn{4}{|l|}{ Season } \\
\hline & Spring & 461 & 24.5 \\
\hline & Summer & 508 & 27.1 \\
\hline & Autumn & 515 & 27.4 \\
\hline & Winter & 394 & 21.0 \\
\hline \multicolumn{4}{|l|}{ Time of accident } \\
\hline & $0-5: 59$ & 37 & 2.0 \\
\hline & $6-11: 59$ & 513 & 27.3 \\
\hline & $12-16: 59$ & 573 & 30.5 \\
\hline & $17-23: 59$ & 755 & 40.2 \\
\hline \multicolumn{4}{|l|}{ Vehicle type } \\
\hline & Car & 453 & 24.1 \\
\hline & Heavy car & 18 & 1.0 \\
\hline & Motorcycle & 1407 & 74.9 \\
\hline
\end{tabular}

Collision types are presented in table 3 . As data in table 3 shows, the accidents with the highest frequency were those of a motorcycle with a car $(n=913,48.6 \%)$. It was also observed that in the majority of accidents, one of the vehicles involved was a motorcycle $(\mathrm{n}=$
1076, 56.2\%). Frequency distribution of type of vehicle involved in the accidents based on the severity of injury is presented in table 4 . There were 4 deceased cases among those injured in MVAs.

Table 2: Association between age and type of vehicle

\begin{tabular}{|c|c|c|c|c|c|c|c|}
\hline \multirow{2}{*}{\multicolumn{2}{|c|}{ Type of accident }} & \multicolumn{6}{|c|}{ Age group } \\
\hline & & \multirow{2}{*}{$\frac{\text { 0-14 year }}{9}$} & \multirow{2}{*}{$\frac{15-29 \text { year }}{52}$} & \multirow{2}{*}{$\frac{30-45 \text { year }}{47}$} & \multirow{2}{*}{$\frac{\text { 46-65 year }}{17}$} & \multirow{2}{*}{$\frac{>65 \text { year }}{6}$} & \multirow{2}{*}{$\frac{\text { Total }}{131}$} \\
\hline & $\mathrm{N}$ & & & & & & \\
\hline Car & $\%$ & 6.0 & 4.9 & 12.2 & 8.4 & 8.1 & 7.0 \\
\hline \multirow{2}{*}{ Motorcycle } & $\mathrm{N}$ & 39 & 617 & 167 & 71 & 19 & 913 \\
\hline & $\%$ & 25.8 & 57.9 & 43.3 & 35.1 & 25.7 & 48.6 \\
\hline \multirow{2}{*}{ Pedestrians } & $\mathrm{N}$ & 65 & 85 & 61 & 75 & 35 & 321 \\
\hline & $\%$ & 43.0 & 8.0 & 15.8 & 37.1 & 47.3 & 17.1 \\
\hline \multirow{2}{*}{ Rollover } & $\mathrm{N}$ & 30 & 248 & 78 & 30 & 10 & 396 \\
\hline & $\%$ & 19.9 & 23.3 & 20.2 & 14.9 & 13.5 & 21.1 \\
\hline \multirow{2}{*}{ Other } & $\mathrm{N}$ & 8 & 63 & 33 & 9 & 4 & 117 \\
\hline & $\%$ & 5.3 & 5.9 & 8.5 & 4.5 & 5.4 & 6.2 \\
\hline \multirow{2}{*}{ Total } & $\mathrm{N}$ & 151 & 1065 & 386 & 202 & 74 & 1878 \\
\hline & $\%$ & 100 & 100 & 100 & 100 & 100 & 100 \\
\hline
\end{tabular}


Table 3: Frequency distribution of accidents based on the type of collision

\begin{tabular}{lcccc}
\hline Type of collision & Frequency & Percentage & Valid percent & Cumulative percentage \\
\hline Car-Pedestrian & 209 & 11.1 & 11.1 & 11.1 \\
\hline Car-Motorcycle & 913 & 48.6 & 48.6 & 59.7 \\
\hline Heavy car-Motorcycle & 14 & 0.7 & 0.7 & 60.5 \\
\hline Car-Barrier & 52 & 2.8 & 2.8 & 63.3 \\
\hline Motorcycle-Barrier & 17 & 0.9 & 0.9 & 64.2 \\
\hline Car-car & 131 & 7.0 & 7.0 & 71.1 \\
\hline Heavy car-Car & 21 & 1.1 & 1.1 & 72.3 \\
\hline Bicycle-Heavy car & 12 & 0.6 & 0.6 & 72.9 \\
\hline Bicycle-Barrier & 1 & 0.1 & 0.1 & 72.9 \\
\hline Motorcycle-Pedestrian & 112 & 6.0 & 6.0 & 78.9 \\
\hline Overturn & 396 & 21.1 & 21.1 & 100 \\
\hline Total & 1878 & 100 & 100 & \\
\hline
\end{tabular}

Moreover, $50 \%$ of deceased cases $(n=2)$ were injured by personal cars and the remaining were injured by motorcycles $(n=2)$. Of the 1386 victims of accidents due to motorcycles, about $30 \%$ were severely injured $(n=410)$. More than $90 \%$ of accidents by bicycles resulted in mild injuries and less than $10 \%$ of individuals riding bicycles were severely injured in the accidents. No significant difference was observed between the severities of accidents by different vehicles (Table 4).

Table 4: Frequency distribution of type of vehicle based on the severity of injuries

\begin{tabular}{lccccccc}
\hline \multirow{2}{*}{ Severity } & \multicolumn{7}{c}{ Type } \\
\cline { 2 - 9 } & & Car & Heavy car & Motorcycle & Bicycle & Tractor & Total \\
\hline \multirow{2}{*}{ Minor } & $\mathrm{N}$ & 298 & 9 & 974 & 19 & 3 & 1303 \\
\cline { 2 - 9 } & $\%$ & 65.5 & 60.0 & 70.3 & 90.5 & 100 & 69.4 \\
\hline \multirow{2}{*}{ Severe } & $\mathrm{N}$ & 153 & 6 & 410 & 2 & 0 & 571 \\
\cline { 2 - 9 } & $\%$ & 33.8 & 40.0 & 29.6 & 9.5 & 0.0 & 30.4 \\
\hline \multirow{2}{*}{ Death } & $\mathrm{N}$ & 2 & 0 & 2 & 0 & 0 & 4 \\
\cline { 2 - 9 } & $\%$ & 0.4 & 0.0 & 0.1 & 21 & 3 & 1878 \\
\hline \multirow{2}{*}{ Total } & $\mathrm{N}$ & 453 & 15 & 1386 & 100 & 100 & 100 \\
\cline { 2 - 9 }
\end{tabular}

\section{Discussion}

Disabilities and death related to injuries are the most tragic phenomena in the present day. In other words, injuries (intentional and/or unintentional) are among the most common public health problems. As a result, public health has an important role to play in continuing the research for a better understanding of injuries $(3,6)$. In this study, we found that men were injured more than women, as injury in men was more than six times that in women. The majority of the victims $(56.7 \%)$ were the in the age group of 15-29 years. Many previous epidemiological 
studies declared that the majority of victims were young and middle aged; moreover, there was a higher rate of injuries in men than women $(11,13,14)$. The study by Dura et al. showed that the frequency of injuries in women and men were $32 \%$ and $68 \%$, respectively. Furthermore, the mean age of victims was $34.8 \pm 17.3$ years, with an age range of 3 months to 87 years (15).

Another study in Mexico on victims of traffic accidents, reported that $54 \%$ of injured individuals had been injured in MVSs (16). In addition, $59.3 \%$ of those injured in MVSs were under 29 years of age, and $70.39 \%$ were men and $29.61 \%$ were women (16). Results obtained in the present study, with respect to sex and age, are i agreement with those reported in other studies $(17,18)$. There was no difference between the different seasons, although the number of accidents which had occurred in summer and autumn was higher than winter and spring. Also results show that the majority of accidents occur in the 17 hours before midnight. The study by Charkazi et al. found that most accidents occur in the summer and autumn (19), which was in agreement with the results of the present study.

Results presented in table 2 show that most victims were in the age group of 15-29 years and had had an accident with a motorcycle. However, in the age groups of younger than 15 years and older than 65 years, the majority of victims had been a pedestrian at the time of the accident. This indicates the need for education for the age group of 15-29 years in relation to the safe use of motorcycles. The second reason for accidents in the age group of 15-29 years was rollover, indicating the high speed of the vehicle and their inability to control the car. This age group in turn, is deserved to be trained for driving, according to the training instructions issued by government. Charkazi et al. found that the age group of 13-29 years, with $63.9 \%$ traffic accidents, had the highest rate of victims (19). Nóbrega et al. analyzed 2570 patients who had had traffic accidents and found that $67.8 \%$ were motorcyclists (13).
This result is in accordance with the findings of the current study.

As table 3 shows, the highest percentage of victims were involved in a car collision with a motorcycle. The results showed that motorcyclists in the city are a major factor in accidents; therefore, the use of appropriate interventions for these individuals is essential to reduce injuries. An important intervention is the training of traffic laws and regulations. Car collision with a pedestrian is important and represents pedestrians' use of unsafe passages. Our findings show that the most recorded accidents $(75 \%)$ had been occurred by motorcycles that illustrates motorcycles are being used frequently in the area of this study. Our study revealed that MVAs constituted the majority of injuries in this district of Kerman Province. Among the MVAs, motorcycle accidents were the most common causes of injuries. Thus, in fact, motorcyclists can be classified as a vulnerable group of the population in this region of Iran.

Palaver et al also found that $67.7 \%$ of collisions were with motorcycles, and the most frequent type of collision by vehicles was motorcycle-car on city streets with $42 \%$ (20). Spoerri et al. found that only $15.7 \%$ of MVAs were motorcycle accidents. Moreover, $16.0 \%$ of victims were pedestrians (21). Hayakawa et al. showed that the percentage of fatal vehicle collisions with pedestrians were higher in Japan than in the United States $(28.5 \%$ vs. $18.2 \%$ ) (22). According to a study conducted by Dilek Durak et al., trauma was most commonly sustained within the motor vehicle (15).

To reduce this type of accident, it is recommended that pedestrian use overpasses or underpasses. Rollovers are a major cause of traffic accidents and indicate the high speed of drivers. Training regulations and traffic laws to reduce these types of accidents can be a great help.

As shown in table 4, although the number of accidents by heavy cars is small, they result in a high percentage of severe injuries, which is an indication for the necessity of action in this 
regard. More than a third of accidents with cars resulted in severe injuries. Hence, it is necessary that appropriate action be taken to enforce traffic laws and guidelines. The research by Hijar et al. shows that $69.96 \%$ of victims had non-severe injuries and only $30.96 \%$ of victims had severe injuries (16). This finding is in agreement with that of the current research.

\section{Conclusion}

The results of this study could help managers and social planners in the health section, especially police department planners to modify and control the generating factors of MVAs in order to reduce MVAs. MVAs, as important causes of injuries, most frequently occurred by motorcycles in the district studied. Therefore, safety training targeted at motorcyclists would be one of the best interventions for the prevention and controlling of trauma due to MVAs. This intervention could be the most efficient among younger drivers.

\section{Acknowledgments}

The authors would like to thank and fully acknowledge the participants, in particular our colleagues in Pre-hospital Emergency Ward, for making this study possible. The authors would also like thank Occupational Environment Research Center for their financial support.

Conflict of interest: None declared.

\section{References}

1- Moshiro C, Heuch I, Astrøm AN, Setel P, Hemed Y, Kvåle G. Injury morbidity in an urban and a rural area in Tanzania: an epidemiological survey. BMC Public Health 2005; 5:11.

2- Olawale OA, Owoaje ET. Incidence and pattern of injuries among residents of a rural area in South-Western Nigeria: a community-based study. BMC Public Health 2007; 7:246.

3- Mock C, Quansah R, Krishnan R, ArreolaRisa C, Rivara F. Strengthening the prevention and care of injuries worldwide. Lancet 2004; 363(9427):2172-9.

4- Wesson HK, Boikhutso N, Bachani AM, Hofman KJ, Hyder AA. The cost of injury and trauma care in low- and middle-income countries: a review of economic evidence. Health Policy Plan 2014; 29(6):795-808.

5- Zwi AB, Forjuoh S, Murugusampillay S, Odero W, Watts C. Injuries in developing countries: policy response needed now. Trans R Soc Trop Med Hyg 1996; 90(6):593-5.

6- Norton R, Kobusingye O. Injuries. N Engl J Med 2013; 368(18):1723-30.

7- Ameratunga S, Hijar M, Norton R. Roadtraffic injuries: confronting disparities to address a global-health problem. Lancet 2006; 367(9521):1533-40.

8- Sharma BR. Road traffic injuries: a major global public health crisis. Public Health 2008; 122(12):1399-406.

9- Reddy GM, Negandhi H, Singh D, Singh AJ. Extent and determinants of cost of road traffic injuries in an Indian city. Indian $\mathbf{J}$ Med Sci 2009; 63(12):549-56.

10- Mohan D. Road traffic injuries: a stocktaking. Best Pract Res Clin Rheumatol 2008; 22(4):725-39.

11- Afzali S, Saleh A, Seif Rabiei MA, Taheri K. Frequency of alcohol and substance abuse observed in drivers killed in traffic accidents in Hamadan, Iran. Arch Iran Med 2013; 16(4):240-2.

12- Majdzadeh R, Khalagi K, Naraghi K, Motevalian A, Eshraghian MR. Determinants of traffic injuries in drivers and motorcyclists involved in an accident. Accid Anal Prev 2008; 40(1):17-23.

13- Nóbrega LM, Cavalcante GM, Lima MM, Madruga RC, Ramos-Jorge ML, d'Avila S. Prevalence of facial trauma and associated factors in victims of road traffic accidents. Am J Emerg Med 2014; 32(11):1382-6.

14- Kanaan A, Huertas P, Santiago A, Sánchez JA, Martínez P. Incidence of different health factors and their influence on traffic accidents in the province of Madrid, Spain. Leg Med (Tokyo) 2009; 11 Suppl 1:S333-6.

15- Durak D, Fedakar R, Türkmen N, Akgöz S, Baduroğlu E. Road traffic collisions in Bursa, Turkey, during 2003, 2004 and 2005. Injury 2008; 39(5):547-53.

16- Híjar M, Arredondo A, Carrillo C, Solórzano L. Road traffic injuries in an urban area in Mexico. An epidemiological and cost analysis. Accid Anal Prev 2004; 36(1):3742.

17- Batstone MD, Monsour FN, Pattel P, Lynham A, The patterns of facial injury suffered by patients in road traffic accidents: a case controlled study. Int J Surg 2007; $5(4): 250-4$

18- Vorko-Jović A, Kern J, Biloglav Z. Risk factors in urban road traffic accidents. J Safety Res 2006; 37(1):93-8.

19- Charkazi A, Esmaeili A, Garkaz G, Qoreishi Z, Gerey S, Nazari S. Epidemiologic survey 
of road traffic accidents in patients admitted in emergency department of Alejalil Hospital in Aq-Qala city, Golestan province. Journal of Health Ardabil University of Medical Sciences 2012; 3(2):42-9.

20- Paravar M, Hosseinpour M, Salehi S, Mohammadzadeh M, Shojaee A, Akbari H, et al. Pre-Hospital Trauma Care in Road Traffic Accidents in Kashan, Iran. Arch Trauma Res 2013; 1(4):166-71.
21- Spoerri A, Egger M, von Elm E; Swiss National Cohort Study. Mortality from road traffic accidents in Switzerland: longitudinal and spatial analyses. Accid Anal Prev 2011; 43(1):40-8.

22- Hayakawa H, Fischbeck PS, Fischhoff B. Traffic accident statistics and risk perceptions in Japan and the United States. Accid Anal Prev 2000; 32(6):827-35. 